\title{
Hepatic Artery Reconstruction for Hepatic Artery Thrombosis After Orthotopic Liver Transplantation
}

\author{
Katsuhiko Yanaga, MD, Guy Lebeau, MD, J. Wallis Marsh, MD, Robert D. Gordon, MD, \\ Leonard Makowka, MD, PhD, Andreas G. Tzakis, MD, Satoru Todo, MD, Andrei C. Stieber, \\ MD, Shunzaburo Iwatsuki, MD, and Thomas E. Starzl, MD, PhD \\ Department of Surgery, University Health Center of Pittsburgh, University of Pittsburgh, and the \\ Veterans Administration Medical Center, Pittsburgh, Pa. Dr Yanaga is now with Kyushu (Japan) \\ University
}

\section{Abstract}

We evaluated the efficacy of reconstruction of the hepatic artery for intraoperative or postoperative thrombosis in orthotopic liver transplantation. Of 37 grafts with artery thrombosis, $13(35.1 \%, 6$ intraoperative and 7 postoperative) underwent reconstruction of the hepatic artery. The arterial flow was reestablished and maintained in 5 (38.5\%) of the 13. Recurrent thrombosis in the other 8 grafts developed 2 to 24 days (mean, 13.8 days) after transplantation. Reconstruction was successful in $50 \%$ (4/8) of the adults, compared with only $20 \%$ (1/5) of the children.

Satisfactory results were obtained when a definitive cause of thrombosis could be identified. We conclude that early recognition and correction of the cause of hepatic artery thrombosis during or after orthotopic liver transplantation, especially in adults, is often a graft-saving and lifesaving procedure worthy of consideration.

After orthotopic liver transplantation (OLTx), hepatic artery (HA) thrombosis (HAT) remains the most common technical complication that requires retransplantation. ${ }^{1,2}$ In children, HAT accounts for approximately $40 \%$ of the retransplantations. ${ }^{2}$ The incidence of this serious complication generally varies from $9 \%$ to $18 \%, 1,8$ and the mortality approaches $50 \% .{ }^{1}$ Hepatic artery thrombosis typically occurs in the early postoperative course and is usually fatal without retransplantation. The shortage of donor organs remains a major limiting factor in clinical liver transplantation, and thus salvage of a liver allograft, if possible, is of critical importance. This study analyzes our experience with 13 patients in whom HA reconstruction (HAR) was attempted during or after OLTx.

\section{PATIENTS AND METHODS}

During the 1-year period between January 1 and December 31, 1987, 323 patients underwent 389 OLTx procedures (282 in adults and 107 in children) at the University of Pittsburgh (Pa). Of these, 37 grafts $(9.5 \%)$ (16 in adults and 21 in children) developed HAT during or shortly after OLTx. Hepatic artery reconstruction was carried out in 13 patients (4.0\%), during OLTx in 6 and $4.7 \pm 3.5$ days (mean \pm SD) later (range, 1 to 12 days) in 7 patients. In those who developed HAT postoperatively, the diagnosis of HAT was established by arteriography in 3, by Doppler ultrasonography in 1, and at the time of semielective exploratory laparotomy for HA stricture on either Doppler ultrasonography or arteriography in 1 each and for intra-abdominal bleeding in 1 patient. Reconstruction of the

Reprint requests to Department of Surgery, University of Pittsburgh School of Medicine, 5W Falk Clinic, 3601 Fifth Ave, Pittsburgh, PA 15213 (Dr Starzl). 
HA among these patients was carried out as an emergency procedure immediately after the diagnosis of HAT was established. The age among the patients studied ranged from 17 months to 58 years, with a mean of 22.0 years; $6(46.1 \%)$ were male. Charts of these patients were reviewed to evaluate the possible cause of HAT, the technique and timing of HAR, and the outcome.

Baseline immunosuppression was achieved with cyclosporine and corticosteroids. Episodes of allograft rejection were treated with a bolus of intravenous methylprednisolone and/or steroid recycle, and steroid-resistant rejection was treated with OKT3 (Orthoclone; Ortho Pharmaceutical Co, Raritan, NJ). Immediately postoperatively, the pediatric patients received low-molecular-weight dextran intravenously at 5 to $10 \mathrm{~mL} / \mathrm{h}$ for 4 days; heparin, 50 $\mathrm{U} / \mathrm{kg}$ subcutaneously every 12 hours throughout the hospital stay (approximately 4 weeks); aspirin, 20 to $40 \mathrm{mg} / \mathrm{d}$ by mouth or per nasogastric tube for at least 3 months; and dipyridamole (Persantine), 12.5 to $25 \mathrm{mg} / \mathrm{d}$ by mouth for at least 3 months. The above therapy was discontinued if the patient demonstrated clinical or laboratory evidence of coagulopathy. All adult patients who underwent OLTx for Budd-Chiari syndrome received anticoagulation with heparin (5000 U subcutaneously, three times a day), followed by warfarin sodium to maintain the prothrombin time around 18 seconds.

\section{RESULTS}

Table 1 lists the clinical data of the patients who developed HAT during the actual transplant procedure. The possible cause of HAT among these patients included poor inflow related to a triple arterial supply of the native liver in one (patient 1), rotation of the aortohepatic interposition graft in the retropancreatic tunnel in one (patient 2), disseminated intravascular coagulation of the donor in one (patient 4), intimal dissection of the recipient common HA due to excessive traction in one (patient 6), and unknown in two patients (patients 3 and 5). In patient 4 , the donor had died of a gunshot wound to the head, and a biopsy of the kidney revealed extensive microthrombosis of the glomeruli. The liver, however, looked grossly normal and was transplanted into a recipient without technical difficulty. The HA became thrombotic despite good inflow and a technically sound anastomosis.

For these patients with intraoperative HAT, the HA anastomosis was taken down and inspected, and the donor HA was flushed with heparinized saline solution $(10 \mathrm{U} / \mathrm{mL})$. The method of revision of the thrombotic HA consisted of the placement of the aortohepatic interposition graft (patients 1 and 6), untwisting of the aortohepatic interposition graft and revision of the anastomosis (patient 2), revision with (patient 4) or without (patient 5) systemic heparinization, and the replacement of the donor celiac axis and the proximal common hepatic artery with an interposition graft with the use of the donor iliac artery (patient 3).

The HA flow was reestablished successfully in two patients (patients 1 and 2) (33.3\%), after the placement or revision of the aortohepatic interposition arterial graft in one. Patient 2 died of rupture of an infected aortic-donor iliac arterial anastomotic site on posttransplant day 15. In the other four patients, the HA occluded 1 to 8 days (mean, 4.3 days) after transplantation and required retransplantation.

Table 2 lists the clinical data of the patients who developed HAT after OLTx. Possible causative factors included poor inflow related to double arterial supply of the native liver (patient 7), size discrepancy between the donor celiac axis and the donor iliac artery used as an aortohepatic interposition graft (patient 10), end-to-side anastomosis (patient 11), infected donor HA (patient 12), kinking of the anastomosis (patient 13), and unknown (patients 8 and 9). The initial HA anastomosis was between the recipient common HA and 
the donor celiac axis in three patients, between the aortohepatic interposition arterial graft with a donor iliac artery and the donor celiac axis in two, between the recipient right HA originating from the superior mesenteric artery and the donor celiac axis in one, and between the recipient common HA and the donor distal superior mesenteric artery after the foldover technique ${ }^{4}$ in one patient.

In patients 7 and 11, HAT was identified during exploratory laparotomy for HA stricture associated with ischemic liver dysfunction. In patient 12, HAT was an unexpected finding at the time of laparotomy for intra-abdominal bleeding.

In all patients with postoperative HAT, the HA anastomosis was taken down and inspected, and the donor HA was flushed with heparinized saline solution $(10 \mathrm{U} / \mathrm{mL})$. The method of revision of the thrombotic HA consisted of the placement of an aortohepatic interposition graft (patient 7), the replacement of the aortohepatic interposition graft (patients 10 and 11), the replacement of the donor celiac axis and the proximal common hepatic artery with an interposition graft with the use of the donor iliac artery, with or without splenic artery ligation (patients 8, 9, and 12), and the revision of the anastomosis (patient 13). In patient $12,10000 \mathrm{U}$ of streptokinase was administered both intravenously and into the graft hepatic artery as a bolus, before revision of the anastomosis. Histologic examination of the excised donor artery revealed transmural necrotizing arteritis, and culture of the HA yielded Pseudomonas.

Among these patients with postoperative HAT, the diagnosis of posttransplant HAT was established 1 to 12 days (mean, 4.7 days) after transplantation. The HA remained patent in three patients (patients 5 through 7) (42.9\%). Patient 13 died of septicemia 81 days after the second transplant, with a patent HA. In the other four patients, recurrent HAT was confirmed 2 to 24 days (mean, 13.8 days) after transplantation.

Overall, an attempt at reconstruction of HAT during or after OLTx was successful in 5 (38.5\%) of 13 patients. The clinical course of the 5 patients after HAR was indistinguishable from that of patients without HAT, and none developed biliary stricture or liver abscesses after reconstruction. Of these 5 patients, 3 were alive and well with patent HA on repeated Doppler ultrasonography and had normal graft function. The other 2 died of infectious complications with patent HA.

Table 3 lists the correlation between various clinical variables and the outcome of HAR among the patients studied. Resection of the HA was successful in 50\% (4/8) of adults. In children, on the other hand, only one (20\%) of five grafts could be salvaged, after incidental detection of HAT on exploratory laparotomy and revision with administration of streptokinase intravenously and through the HA (patient 12). Although no obvious relationship was observed between the outcome of HAR and the timing of HAT or methods of HAR, grafts with HAT due to mechanical causes responded well to HAR.

\section{COMMENT}

As a general rule in vascular surgery, embolectomy for arterial thromboembolic disease is often satisfactory, where as thrombectomy is seldom effective. ${ }^{5}$ In solid-organ transplantation, little is known about revascularization of the graft with acute arterial occlusion.

For kidney transplants in which the renal artery is the only inflow for the graft, Melzer et al ${ }^{6}$ in 1982 reported successful recovery of allograft function with a revision of the arterial anastomosis after 3 hours 15 minutes of warm ischemia. The cause of arterial occlusion was kinking of the recipient internal iliac artery. Okiye and Zincke ${ }^{7}$ in 1983 described a patient 
whose arterial thrombosis was successfully treated after 5 hours 30 minutes of warm ischemia, with repositioning of the kinked allograft renal artery, intra-arterial injection of heparin, and postoperative systemic heparinization. Acute tubular necrosis in this patient resolved in 13 days.

For liver transplants, Klintmalm et al ${ }^{8}$ in 1988 described three patients with HAT after OLTx in whom attempts were made after transplantation to salvage the grafts by immediate vascular reconstruction. Two patients with kinking of the HA distal to the anastomosis were treated with thrombectomy, a flush of the HA with heparinized saline, and a revision of the HA anastomosis; this resulted in complete recovery of graft function in one, whereas in the other, biliary stricture and hepatic abscess ensued and HAT was confirmed at the time of retransplantation $5 \frac{1}{2}$ months after the initial transplant. In another patient in whom intimal dissection of the donor HA was the cause of HAT, the aortohepatic graft was placed after thrombectomy and a flush with heparinized saline. This patient developed biliary stricture and a hepatic abscess that required surgical drainage. The patency of the HA after the reconstruction was not documented in the two patients who did not undergo retransplantation in that report. The authors stressed the importance of early detection and intervention of HAT after OLTx. Houssin et $\mathrm{al}^{9}$ recently reported successful HAR with emergency laparotomy for disappearance of HA flow signal from a pulsed Doppler microprobe implanted at the time of OLTx.

In this series, 38.5\% (5/13) of the grafts could be salvaged after HAR for HAT during or immediately after OLTx, The poor outcome of HAR in children seems to have been related to the inability to identify an obvious cause of the thrombosis in all but one patient and may be due to a small caliber of the HA with low flow. ${ }^{10,11}$ On the other hand, favorable results were obtained in adults, especially when mechanical causes of HAT were identified (patients 2,11, and 13).

Successful HAR in this series and others ${ }^{8,9}$ seem to demonstrate the importance of early detection of the HAT. After OLTx, emergency Doppler ultrasonography ${ }^{12}$ should be performed when the graft fails to function immediately postoperatively or when postoperative liver function deteriorates suddenly.

Rejection has been known as a cause of HAT after OLTx. ${ }^{1,10}$ In this series, however, no evidence of rejection could be demonstrated among the patients with HAT.

For insufficient arterial inflow due to recipient HA anomaly or hypoplastic recipient artery, an aortohepatic interposition graft has been placed through a retropancreatic route from the infrarenal abdominal aorta, with the use of a donor iliac artery. ${ }^{13}$ Since inflow problem is a correctable cause of HAT, and since palpation of the HA is not a reliable method in the assessment of the adequacy of blood flow through the HA, measurement of the HA blood flow with a flow meter seems important to avoid HAT. ${ }^{14}$

The study described herein seems to indicate that an early recognition of HAT followed by an attempt at reconstruction of the HA for HAT during or after OLTx, especially in adults, is often satisfactory and graft-saving as well as lifesaving.

\section{Acknowledgments}

This study was supported by research grants from the Veterans Administration, Washington, DC, and project grant AM 29961 from the National Institutes of Health, Bethesda, Md. 


\section{References}

1. Tzakis AG, Gordon RD, Shaw BW, Iwatsuki S, Starzl TE. Clinical presentation of hepatic artery thrombosis after liver transplantation in the cyclosporin era. Transplantation 1985;40:667-671. [PubMed: 3907040]

2. Gordon, RD.; Iwatsuki, S.; Esquivel, CO., et al. Liver transplantation. In: Cerilli, GJ., editor. Organ Transplantation and Replacement. Philadelphia, Pa: JB Lippincott Co; 1988. p. 530-581.

3. Tisone G, Gunson BK, Buckels JAC, McMaster P. Raised hematocrit: a contributing factor to hepatic artery thrombosis following liver transplantation. Transplantation 1988;46:162-163. [PubMed: 3293279]

4. Gordon RD, Shaw BW Jr, Iwatsuki S, Todo S, Starzl TE. A simplified technique for revascularization of homografts of the liver with a variant right hepatic artery from the superior mesenteric artery. Surg Gynecol Obstet 1985;160:474-476. [PubMed: 3887623]

5. Salzman, EW. Surgical treatment of arterial thromboembolic disease. In: Colman, RW.; Hirsh, J.; Marder, VJ.; Salzman, EW., editors. Hemostasis and Thrombosis. Philadelphia, Pa: JB Lippincott Co; 1987. p. 1467-1474.

6. Melzer JS, Sicard GA, Etheredge EE, Anderson CB. Successful revascularization of early posttransplant renal arterial occlusion. Surgery 1982;91:168-172. [PubMed: 7036393]

7. Okiye SE, Zincke H. Renal allograft salvage after prolonged early posttransplant renal artery occlusion. J Urol 1988;129:1216-1217. [PubMed: 6343639]

8. Klintmalm GB, Olson LM, Nery JR, Husberg BS, Paulsen AW. Treatment of hepatic artery thrombosis after liver transplantation with immediate vascular reconstruction: a report of three cases. Transplant Proc 1988;20:610-612.

9. Houssin D, Dupuy P, Vigouroux C, Payen DM, Chapuis Y. Eight days monitoring of portal and hepatic arterial blood flows after liver transplantation using implantable pulsed doppler microprobes. Transplant Proc 1989;21:2277-2278. [PubMed: 2652737]

10. Esquivel CO, Koneru B, Karrer F, et al. Liver transplantation before 1 year of age. J Pediatr 1987;110:545-548. [PubMed: 3550022]

11. Yanaga K, Makowka L, Shimada M, et al. Hepatic artery thrombosis following pediatric liver transplantation: assessment of blood flow measurement in allografts. Clin Transplant 1989;8:184189. [PubMed: 21151746]

12. Segel MC, Zajko AB, Bowen A, et al. Doppler ultrasound as a screen for hepatic artery thrombosis after liver transplantation. Transplantation 1986;41:539-541. [PubMed: 3515656]

13. Shaw BW, Iwatsuki S, Starzl TE. Alternative methods of arterialization of the hepatic graft. Surg Gynecol Obstet 1984;159:490-498. [PubMed: 6387980]

14. Yanaga K, Shimada M, Makowka L, Esquivel CO, Tzakis AG, Starzl TE. Significance of blood flow measurement in clinical liver transplantation. Transplant Proc 1989;21:2330-2331. [PubMed: 2652755] 


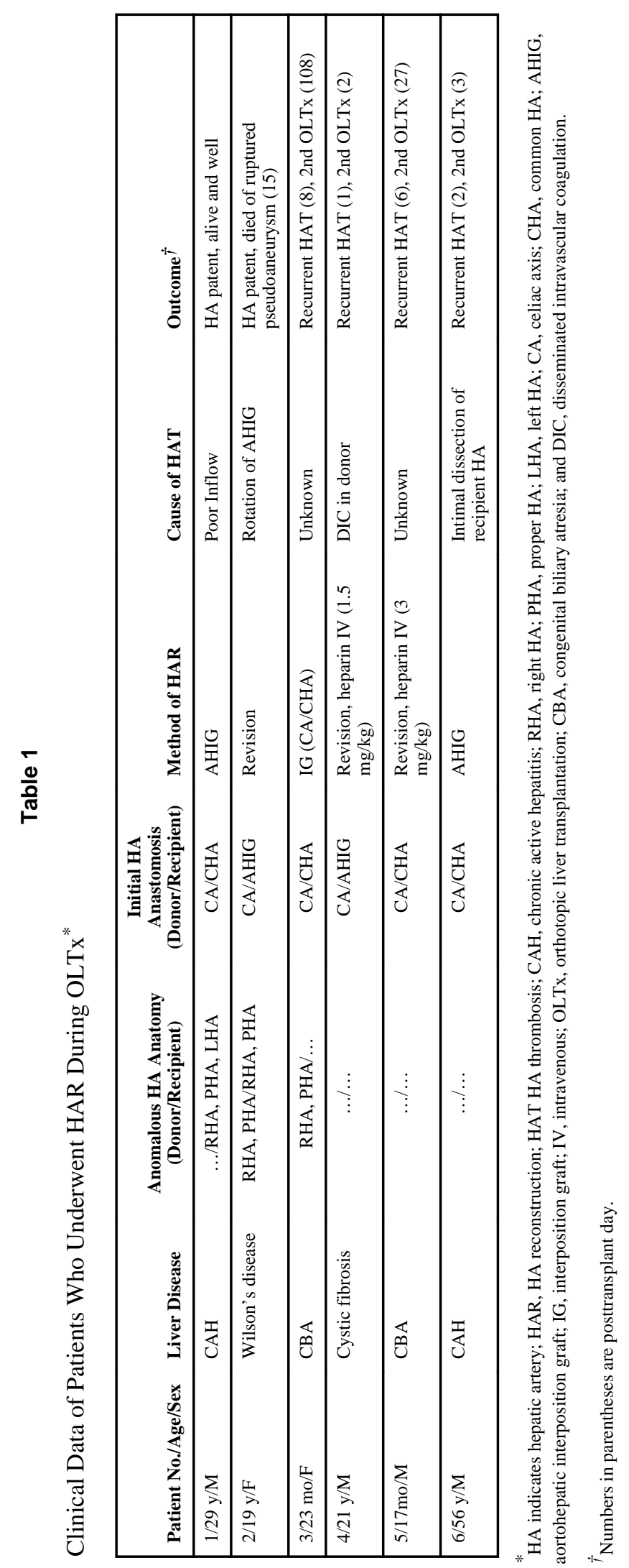




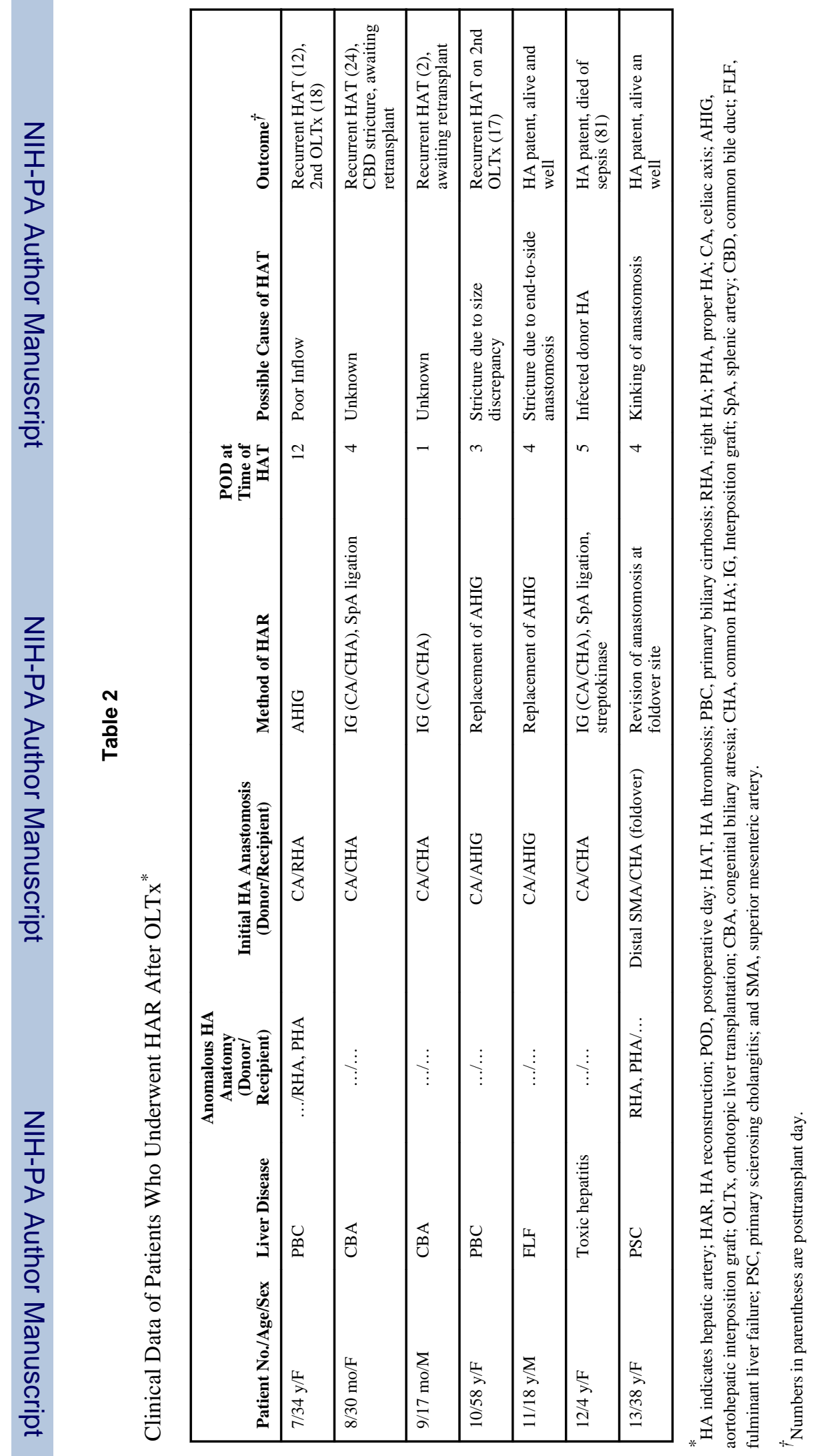

Arch Surg. Author manuscript; available in PMC 2011 January 6. 
Table 3

Correlation Between Clinical Variables and Outcome of HAR During or After Orthotopic Liver Transplantation*

\begin{tabular}{|c|c|c|}
\hline & \multicolumn{2}{|c|}{ Outcome, No. $(\%)$} \\
\hline & Patent HA & Recurrent HAT \\
\hline \multicolumn{3}{|l|}{ Age group } \\
\hline Adults $(\mathrm{n}=8)$ & $4(50)$ & $4(50)$ \\
\hline Children $(n=5)$ & $1(20)^{\dagger}$ & $4(80)$ \\
\hline \multicolumn{3}{|l|}{ Time of HAT } \\
\hline Intraoperative $(\mathrm{n}=8)$ & $2(33.3)$ & $4(66.7)$ \\
\hline Postoperative $(n=7)$ & $3(42.9)$ & $4(57.1)$ \\
\hline \multicolumn{3}{|l|}{ Method of HAR } \\
\hline Revision of anastomosis $(n=4)$ & $2(50)$ & $2(50)$ \\
\hline Placement of AHIG $(n=3)$ & $1(33.3)$ & $2(66.7)$ \\
\hline Replacement of AHIG $(n=2)$ & $1(50)$ & $1(50)$ \\
\hline Placement of IG between donor and recipient artery $(n=4)$ & $1(25)$ & $3(75)$ \\
\hline \multicolumn{3}{|l|}{ Cause of HAT } \\
\hline Mechanical $(\mathrm{n}=5)$ & $3(60)$ & $2(40)$ \\
\hline Poor inflow $(\mathrm{n}=2)$ & $1(50)$ & $1(50)$ \\
\hline Unknown $(\mathrm{n}=4)$ & $0(0)$ & $4(100)$ \\
\hline Others $(\mathrm{n}=2)$ & $1(50)$ & $1(50)$ \\
\hline
\end{tabular}

* HA indicates hepatic artery; HAT, HA thrombosis; HAR, HA reconstruction; AHIG, aortohepatic interposition graft; and IG, Interposition graft.

${ }^{\dagger}$ HAT was identified as an incidental finding at the time of exploratory laparotomy. 